\title{
O PESSOAL É POLÍTICO? AS REPRESENTAÇÕES SOCIAIS DOS PROFISSIONAIS DA ESTRATÉGIA DA SAÚDE DA FAMÍLIA SOBRE A VIOLÊNCIA CONTRA MULHERES NO MUNICÍPIO DE TRÊS CACHOEIRAS
}

Dione Matos de Souza Cardoso ${ }^{1}$ Graziela Cucchiarelli Werba ${ }^{2}$

Resumo: O Sistema Único de Saúde é a atual forma de organização da assistência pública em saúde em nosso país. Na busca pela reorganização das práticas profissionais foi instituída a ESF Estratégia Saúde da Família. Este artigo tem por objetivo discutir sobre as RS Representações Sociais - dos profissionais da ESF acerca da violência contra as mulheres. A pesquisa foi realizada com as equipes da ESF do município de Três Cachoeiras - RS. Os dados foram obtidos através das técnicas de Grupo Focal, Entrevistas e Observação Participante. Foram delimitadas três categorias: Invisibilidade, Culpabilização e Intervenções. Concluímos que, o setor de saúde ainda não reconhece esta problemática como de sua competência. A categoria culpabilização apontou a "liberdade da mulher" como causa principal da violência de gênero, sinalizando a necessidade de uma reflexão acerca do principal objetivo do movimento feminista, a "libertação feminina".

Palavras-chave: Mulher. Violência. Gênero. Saúde.

\begin{abstract}
The public healthcare system is the current form of organization of public healthcare in our country. FHS - Family Health Strategy has been established in order to organize professional practices in the public healthcare system. This paper aims to discuss the SR - Social Representations - of the FHS professionals about violence against women. The research was conducted with the FHS team from Três Cachoeiras - RS. The data was obtained using Focal Groups, Interviews and Participant Observation techniques.
\end{abstract}

\footnotetext{
${ }^{1}$ Especialista em Gestão Comunitária e Saúde Mental, docente e coordenadora adjunta do curso de Psicologia ULBRA - Torres.

${ }^{2}$ Pós Doutora em Psicologia, docente e coordenadora do Curso de Psicologia da Universidade Luterana do Brasil (ULBRA).
} 


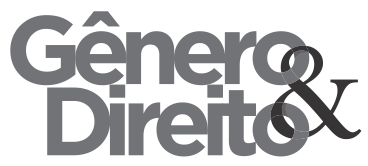

Three categories have been delimited: Invisibility, Blaming and Interventions. We conclude that the health sector does not recognize this issue as their responsibility. The Blaming category pointed the "woman freedom" as the main cause of the gender violence, showing the necessity of a reflection about the main goal of the feminist movement, the "feminine liberation".

Keywords: Women. Violence. Gender. Health.

\section{INTRODUÇÃO}

O Sistema Único de Saúde é a atual forma de organização da assistência pública em saúde em nosso país. Com o propósito de descentralização e capilaridade, o programa de Atenção Básica foi desenvolvido para que a saúde estivesse mais próxima da vida das pessoas, sendo a porta de entrada para toda a Rede de Atenção à Saúde. Na busca pela reorganização das práticas profissionais e reconhecimento dos territórios e suas especificidades a portaria 648 do ano de 2006 institui a política Programa Saúde da Família - PSF e os princípios gerais da Estratégia Saúde da Família.

Historicamente, no contexto da saúde, o estatuto biológico da mulher esteve sempre associado a outro, moral e metafísico. As diferenças entre homens e mulheres, constatadas pelos médicos, não se dava somente por um conjunto de órgãos, mas também por sua natureza e características morais. $\mathrm{O}$ debate sobre a saúde da mulher nas últimas três décadas, alinhavado pela reforma sanitária e pela atuação do movimento feminista, centrouse inicialmente no tema do controle demográfico. Dentro da concepção de atenção integral a saúde das mulheres a violência contra mulheres, ou violência de gênero, é reconhecida como um problema de saúde pública. Segundo Guedes, Fonseca e Egry (2013) a alta prevalência da violência de gênero entre mulheres usuárias dos serviços básicos de saúde foi constatada tanto em estudos nacionais como internacionais, apontando que 35\% das queixas que levam as mulheres ao serviço de saúde estão relacionadas com algum tipo de violência.

O presente artigo, resultante de uma pesquisa-ação realizada com as equipes da ESF - Estratégia Saúde da Família do município de Três Cachoeiras, Rio Grande do Sul, tem por objetivo discutir sobre as representações sociais destes profissionais acerca da violência 


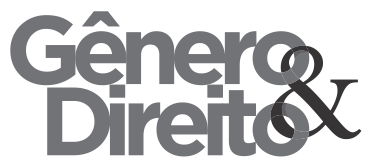

Periódico do Núcleo de Estudos e Pesquisas sobre Gênero e Direito Centro de Ciências Jurídicas - Universidade Federal da Paraíba

V. 6 - $\mathrm{N}^{\circ} 02$ - Ano 2017

ISSN | 2179-7137 | http://periodicos.ufpb.br/ojs2/index.php/ged/index

contra as mulheres. Os dados foram obtidos através das técnicas de Grupo Focal, Entrevistas e Observação Participante. A partir do tratamento do material foram delimitadas três categorias: Invisibilidade, Culpabilização e Intervenções. Para discutir estes achados, retomamos historicamente a construção das políticas de saúde e sua interseção com a história das mulheres, apontando a violência de gênero como um problema pertencente à saúde pública. Tal análise foi concebida a partir dos pressupostos da Psicologia Social Crítica, tendo como pano de fundo as teorias de Gênero e Representações Sociais.

\section{MÉTODOS}

Este estudo trata de uma pesquisa - ação, de abordagem qualitativa, realizada em quatro Unidades de Saúde que trabalham como ESF - Estratégia Saúde da Família no município de Três Cachoeiras, Rio Grande do Sul. Após aprovação do Comitê de Ética em Pesquisa com Seres Humanos, parecer número 735.120, os dados foram coletados através das técnicas de Grupo Focal, Entrevistas e Observação Participante. Ao total foram realizados quatros grupos focais, sendo dois com oito participantes e dois com dez participantes. As entrevistas foram realizadas individualmente, com oito participantes: dois médicos, duas enfermeiras, duas técnicas de enfermagem e duas agentes comunitárias de saúde. A observação participante foi realizada durante reuniões de equipes e ao longo de todo o processo de coleta de dados. Todos os sujeitos entrevistados nesta pesquisa atuam nas equipes da saúde da família denominadas ESF1, ESF2, ESF3 e ESF 4, sendo duas instaladas em seus territórios e outras duas na Unidade de Saúde Central Dr. Paim Cruz, na sede do município, localizada à Rua Damázio José Scheffer, no 138 Bairro Centro. As equipes são compostas por médico, enfermeira, técnicas de enfermagem e agentes comunitárias de saúde, totalizando quarenta pessoas. 


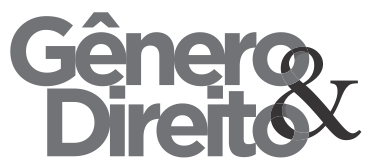

Os Grupos Focais foram realizados na Unidade Básica de Saúde Central denominada ESF 2, respeitando os requisitos éticos da pesquisa com seres humanos e com aprovação do Comitê de Ética em Pesquisa da Universidade Luterana do Brasil. Durante a realização dos grupos focais foram lançadas as mesmas perguntas: "O que vocês compreendem sobre violência contra mulher? Como vocês lidam em seu trabalho com essa problemática?" O material obtido dos grupos foi gravado, transcrito, categorizado e analisado através das teorias das Representações Sociais e Gênero. As entrevistas também foram gravadas e transcritas, juntando-se ao material para igual forma de apreciação.
Cenco do Núcleo de Estudos e Pesquisas sobre Gênero e Direito Centro de Ciências Jurídicas - Universidade Federal da Paraíba V. 6 - $\mathrm{N}^{\circ} 02$ - Ano 2017

A análise de conteúdo foi elaborada a partir de três polos: a pré análise, a exploração do material e o tratamento dos resultados. Após a análise do material, percebemos que a subcategoria "Liberdade das mulheres como causa de violência" poderia e deveria ser melhor investigada. Dessa forma, realizamos novo grupo focal com a frase estímulo "Vocês acreditam que a liberdade conquistada pelas mulheres pode ser um fator gerador de violência de gênero?”.

A categorização, através da temática de Bardin (1997), nos permitiu a passagem dos dados brutos a dados organizados, apontando o seguinte conjunto de categorias e subcategorias:

\begin{tabular}{|l|l|l|}
\hline Invisibilidade & Culpabilização & Intervenções \\
\hline Normalidade & $\begin{array}{l}\text { Liberdade das mulheres como causa } \\
\text { da violência }\end{array}$ & Acolhimento/escuta \\
\hline Acomodação/submissão & Transtornos afetivos & \\
\hline Medo & & \\
\hline
\end{tabular}




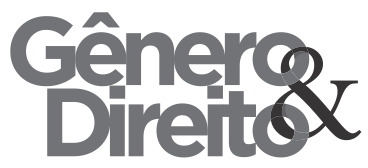

O critério de categorização semântica nos permitiu a constituição de um conjunto onde reunimos elementos temáticos e seus significados. Desta forma, o material tratado apontou as seguintes categorias: Invisibilidade, Culpabilização e Intervenções.

\section{POLÍTICAS DE SAÚDE}

O SUS - Sistema Único de Saúde - é a atual forma de organização da assistência pública em saúde em nosso país. Resultante do Movimento pela Reforma Sanitária, foi instituído oficialmente na promulgação da Constituição Federal de 1988. Sua operacionalização fundamenta-se a partir de três diretrizes: a descentralização, a integralidade e o controle/participação social (DIMENSTEIN, 2007).

Dentro destes conceitos, a Política Nacional de Atenção Básica (PNAB) é resultado da experiência acumulada por um conjunto de atores envolvidos historicamente com o desenvolvimento e a consolidação do Sistema Único de Saúde (SUS), como movimentos sociais, usuários, dico do Núcleo de Estudos e Pesquisas sobre Gênero e Direito Centro de Ciências Jurídicas - Universidade Federal da Paraíba V. 6 - $\mathrm{N}^{\circ} 02$ - Ano 2017 180

trabalhadores e gestores das três esferas de governo.

No Brasil, a Atenção Básica é desenvolvida com o mais alto grau de descentralização e capilaridade, ocorrendo no local mais próximo da vida das pessoas. Ela deve ser o contato preferencial dos usuários, a principal porta de entrada e centro de comunicação com toda a Rede de Atenção à Saúde. Por isso, é fundamental que ela se oriente pelos princípios da universalidade, da acessibilidade, do vínculo, da continuidade do cuidado, da integralidade da atenção, da responsabilização, da humanização, da equidade e da participação social (BRASIL, 2012).

$\mathrm{Na}$ busca pela reorganização das práticas profissionais e reconhecimento dos territórios e suas especificidades, a portaria 648 do ano de 2006 institui a política Programa Saúde da Família - PSF. O capítulo II da resolução assinala as especificidades e princípios gerais da Estratégia Saúde da Família:

1 - PRINCÍPIOS GERAIS

A estratégia de Saúde da Família visa a reorganização da Atenção Básica no País, de acordo com os preceitos do Sistema Único de Saúde. Além dos princípios gerais da Atenção Básica, a estratégia Saúde da Família deve: 
I - ter caráter substitutivo em relação à rede de Atenção Básica tradicional nos territórios em que as Equipes Saúde da Família atuam;

II - atuar no território, realizando cadastramento domiciliar, diagnóstico situacional, ações dirigidas aos problemas de saúde de maneira pactuada com a comunidade onde atua, buscando o cuidado dos indivíduos e das famílias ao longo do tempo, mantendo sempre postura pró-ativa frente aos problemas de saúde-doença da população;

III - desenvolver atividades de acordo com o planejamento e a programação realizados com base no diagnóstico situacional e tendo como foco a família e a comunidade;

IV - buscar a integração com instituições e organizações sociais, em especial em sua área de abrangência, para o desenvolvimento de parcerias; e V - ser um espaço de construção de cidadania. (BRASIL, 2006)

A Estratégia Saúde da Família visa à reorganização da atenção básica no País, de acordo com os preceitos do Sistema Único de Saúde, e é tida pelo Ministério da Saúde e gestores estaduais e municipais, representados respectivamente pelo Conass e Conasems, como estratégia de expansão, qualificação e consolidação da atenção básica por favorecer uma reorientação do processo de trabalho com maior potencial de aprofundar os princípios, diretrizes e fundamentos da atenção básica, de ampliar a resolutividade e o impacto na situação de saúde das pessoas e coletividades, além de propiciar uma importante relação custoefetividade.

A equipe multiprofissional Saúde da Família é composta por, no mínimo, médico generalista ou especialista em Saúde da Família ou médico de Família e Comunidade, enfermeiro generalista ou especialista em Saúde da Família, auxiliar ou técnico de enfermagem e agentes comunitários de saúde.

Cada equipe deve ser responsável por, no máximo, 4.000 pessoas, sendo que, quanto maior o grau de vulnerabilidade das famílias daquele território, menor deverá ser a quantidade de pessoas (usuários) por equipe. $\mathrm{O}$ número de Agentes Comunitárias de Saúde - ACS deve ser suficiente para cobrir $100 \%$ da população cadastrada, com um máximo de 750 pessoas por ACS.

\section{MULHERES E SAÚDE: UMA HISTÓRIA}

A história das mulheres é marcada pela invisibilidade, sua imagem, no contexto histórico é permeada por mitos, pela dicotomia entre os gêneros, e por imagens que foram escritas e descritas por homens e que ainda encontram-se 


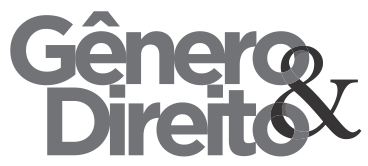

enraizadas no imaginário até os dias de hoje.

A historiadora Mary Del Priore tem resgatado, em suas obras, esta história perdida ao longo do tempo. A autora, ao procurar dar visibilidade à mulher na História do Brasil, vai buscar no período colonial as raízes do "machismo" e amplia a visão dos estereótipos perpetuados na história do nosso país sobre as mulheres.

A história das mulheres no período colonial revela uma série de fatores que se cristalizaram, deixando grandes marcas de diferenças de gênero que ainda hoje perduram no imaginário brasileiro.

$\begin{array}{ccc} & \text { Priore (2009) } & \text { apresenta o } \\ \text { período colonial através do }\end{array}$
entrecruzamento das mais variadas etnias, diálogos entre visões de mundo diferentes, costumes, hábitos e crenças marcados pela alteridade, fecundando a condição feminina, na Terra de Santa Cruz. A autora revela que, da mulher indígena herdava-se as tradições tribais e da mulher branca os modos de viver e morrer importados da emigração portuguesa. As sociedades africanas transmitiram à vida colonial comportamentos e mentalidades características do espaço que a mulher ódico do Núcleo de Estudos e Pesquisas sobre Gênero e Direito Centro de Ciências Jurídicas - Universidade Federal da Paraíba

V. 6 - $\mathrm{N}^{\circ} 02$ - Ano 2017

182

ocupava em seu interior. A condição feminina era marcada pelo caráter exploratório do império português, grande parte do contingente feminino, a quem a Igreja e o Estado recomendavam que se casasse e constituísse família, chegava aos homens pelo caminho da exploração ou da escravização, acentuando, nas suas desigualdades, as relações de gênero.

A autora (p:22) segue argumentando que:

Tais diferenças foram importantes na constituição dos papéis femininos e serviram de estereótipos bastante utilizados pela sociedade colonial e mais tarde incorporados pela historiografia. As marcas desse penoso caminho feito de preconceito e estigmas sociais tanto se refletiam nas relações entre os sexos, quanto acentuavam as diferenças entre as próprias mulheres.

Ainda nos primeiros tempos da colonização, as questões sobre saúde e doença provinham de crenças que brotavam no imaginário. Segundo Priore (2007) as doenças eram consideradas um justo castigo, por infrações e infidelidades perpetradas pelos seres humanos. $\mathrm{O}$ médico era um criador de conceitos que ultrapassava o domínio da medicina propriamente dita. O estatuto biológico da mulher estava sempre associado a outro, 
moral e metafísico. As diferenças biológicas entre homens e mulheres, constatadas pelos médicos, tornava as mulheres seres de natureza suave e terna. "Para a maior parte dos médicos, a mulher não se diferenciava do homem apenas por um conjunto de órgãos específicos, mas também por sua natureza e por suas características morais (p:79)".

Nos séculos XVI e XVII, os jesuítas, o Tribunal do Santo Ofício e a Coroa uniram-se contra qualquer nova iniciativa científica ou cultural, considerando-as, todas, pura heresia. Nesse ambiente de atraso científico e de crença em poderes mágicos capazes de atacar a saúde é que argumentos e noções sobre o funcionamento do corpo da mulher foram fabricados.

O conhecimento limitado permeado pelo imaginário transformou o útero, denominado de madre, um território misterioso capaz de produzir enfermidades quando não executasse a função reprodutiva.

$\mathrm{Na}$ tentativa de isolar os fins aos quais a natureza feminina deveria obedecer, os médicos reforçavam tão somente a ideia de que o estatuto biológico da mulher (parir e procriar) estaria ligado a um outro, moral e metafísico: ser mãe, frágil e submissa, ter bons sentimentos etc. Convém notar que a valorização da sexualidade feminina, mas não no sentido da sua realização e sim no de sua disciplina (p: 83).

O debate sobre a saúde da mulher nas últimas três décadas, alinhavado pela reforma sanitária e pela atuação do movimento feminista, centrou-se inicialmente no tema do controle demográfico. De um lado, a Igreja com sua visão dogmática sobre o assunto, do outro o controle da fecundidade com farta distribuição de pílulas contraceptivas e cirurgias de esterilização.

Em 1983 o Ministério da Saúde criou o PAISM - Programa de Assistência Integral à Saúde das Mulheres, instituindo a participação do Estado através da política específica de atenção à mulher e aos casais, incluindo o planejamento familiar.

Especificamente no tocante à assistência, o PAISM inova ao propor formatos de organização de serviços abrangentes, nucleados pela abordagem da mulher como sujeito integral. Este modelo recomenda a incorporação de ações para o cuidado da saúde, nas suas diferentes fases e necessidades, com forte componente educativo voltado para a promoção da consciência e autonomia sobre o corpo, a sexualidade e a saúde (COSTA E SILVESTRE, 2009, p: 64). 
Mesmo incorporado ao SUS, o

PAISM não pôde avançar de forma significativa, seguindo de maneira restrita à oferta de determinadas ações de saúde, muitas vezes remetidas a uma "intenção de ser integral” sem alcançar a real efetivação.

$\mathrm{O}$ conceito de integralidade em saúde vem recebendo contribuições permanentes, tencionando os saberes e fazeres nas práticas e políticas de atenção às mulheres.

Como assinala Costa e Silvestre (2009, p: 67):

\begin{abstract}
A integralidade da atenção às mulheres envolve transformação das práticas de cuidado pautadas pela universalidade do acesso, equidade com atenção diferenciada para grupos vulneráveis e qualidade, do cuidado, nas suas múltiplas dimensões. Advém do sentido de integrar, e esse sentido deve estar movido pela ética da solidariedade e do reconhecimento da dor do outro, portanto, do outro como merecedor de compaixão.
\end{abstract}

É dentro desta concepção de atenção integral a saúde das mulheres que a violência contra mulheres, ou violência de gênero, é reconhecida como um problema de saúde pública.

A Organização Mundial da Saúde (OMS) reconhece a violência doméstica como um problema de saúde pública, pois afeta a integridade física e a saúde mental. Os efeitos da violência doméstica, sexual e racial sobre a saúde física e mental das mulheres, são evidentes para quem trabalha na área. Mulheres em situação de violência frequentam com assiduidade os serviços de saúde e em geral com "queixas vagas".

Segundo Guedes, Fonseca e Egry (2013) a alta prevalência da violência de gênero entre mulheres usuárias dos serviços básicos de saúde foi constatada tanto em estudos nacionais como internacionais, apontando que 35\% das queixas que levam as mulheres ao serviço de saúde estão relacionadas com algum tipo de violência.

Esta realidade é vivenciada pelos profissionais das equipes de saúde que, apesar de reconhecerem a importância de acolher as mulheres que trazem esta demanda, sentem-se impotentes e temerosos diante das situações. A desinformação e a falta de capacitação profissional específica acabam por reforçar a invisibilidade da violência vivenciada pelas mulheres usuárias dos serviços de saúde. Mas estes seriam os únicos entraves na prática de atenção à 


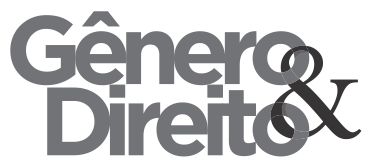

saúde das mulheres em situação de violência de gênero?

\section{DISCUSSÃO DOS RESULTADOS}

A problemática da violência contra mulher, na prática, persiste sem ser reconhecida como pertencente à área da saúde. Esta afirmação parte das experiências vivenciadas pelos profissionais que atuam nesta área e são corroboradas por pesquisas que apontam os entraves no atendimento às mulheres que vivem esta situação. Embora saibamos que a capilaridade das unidades básicas de saúde pressupõe o livre acesso a todos os usuários e usuárias, o sistema de saúde e suas equipes mostram-se despreparados para enfrentar essa dura realidade.

Vindas de uma formação em Psicologia Socio-Histórico-Crítica e pertencentes ao núcleo de pesquisa da Universidade Luterana do Brasil, onde os estudos sobre a violência contra mulheres são tema central, não pudemos deixar de perceber as angústias vivenciadas pelos
Ceno do Núcleo de Estudos e Pesquisas sobre Gênero e Direito Centro de Ciências Jurídicas - Universidade Federal da Paraíba

V. 6 - $\mathrm{N}^{\circ} 02$ - Ano 2017

profissionais da ESF ao acolher mulheres em situação de violência.

Neste sentido, alguns estudos têm apontado a desinformação, a falta de capacitação e o trabalho pautado no modelo biomédico como os principais entraves para a efetivação de práticas de saúde combatentes à violência contra mulheres. Partindo destes achados, este estudo foi elaborado a fim de que possamos reconhecer, através da teoria das Representações Sociais, a construção do conhecimento produzido pelos profissionais no que se refere ao tema violência contra mulheres ${ }^{3}$.

Strey (2000) afirma que qualquer pessoa que tenha seus direitos mais fundamentais ou mais complexos violados, está diante de uma violência, de um crime contra os direitos humanos. Se este crime ocorre pelo fato da vítima pertencer a determinado gênero, como por exemplo, ser mulher, estamos falando de uma violência de gênero, ou seja, violência contra mulher.

${ }^{3}$ Para os fins da presente Declaração, a expressão "violêniaiduindo as ameaças de tais actos, a coacção ou a privação contra as mulheres" significa qualquer acto de violênołaitrária de liberdade, que ocorra, quer na vida pública, quer na privada.

Disponível em: sofrimento físico, sexual ou psicológico para as mulhehetsp://direitoshumanos.gddc.pt/3_4/IIIPAG3_4_7.htm 
Nesse sentido, Werba (1999, p:

153) salienta que:

A prática da violência como principal meio de subordinação da mulher teve e tem muitas formas, sobrevivendo na história alimentando-se da ignorância, do preconceito, da desigualdade econômica, da injustiça social e principalmente através do controle e cerceamento do corpo feminino, redesenhando definitivamente as estruturas de conhecimento, do poder e da medicina.

Ainda para a autora, as representações socialmente construídas em relação à violência contra a mulher efetivamente reafirmam a banalização e a invisibilidade das situações em que essas mulheres muitas vezes se encontram. As múltiplas discriminações estão presentes no âmbito econômico, social, político, cultural, racial, permitindo e reforçando a violência contra a mulher.

Sobre a construção das RS Representações Sociais - Jodelet (1993, p: 5) declara que:

Igualmente designado como "saber do senso comum" ou ainda "saber ingênuo", "natural", esta forma de conhecimento distingue-se, dentre outros, do conhecimento científico. Mas ela é tida como um objeto de estudo tão legítimo quanto aquele, por sua importância na vida social, pelos esclarecimentos que traz acerca dos processos cognitivos e as interações sociais.
A partir desta perspectiva, as Representações Sociais nos permitem apreender um saber próprio, que se constrói no simbólico e no social, conforme nos assinala Jovchelovitch (2011, p: 259) “todo saber é expressivo, pois procura representar mundos subjetivos, intersubjetivos e objetivos".

É na busca pela objetividade deste saber construído sobre a violência contra mulher, que abordaremos as seguintes categorias apontadas pelas(os) participantes da pesquisa: Invisibilidade, culpabilização e intervenções.

\section{SOBRE A INVISIBILIDADE}

Violência Velada: acomodação ou normalidade?

“Então elas só querem jogar em cima da gente as frustrações né, pra se aliviar e a vida vai continuar do mesmo jeito, no dia seguinte se ir lá vai ta tudo igual, elas mesmo já não querem mais mudar, acho que se acomoda ou se acostuma, sei lá (sic). (ACS - Agente Comunitária de Saúde, participante da pesquisa, Agosto de 2014)”. 


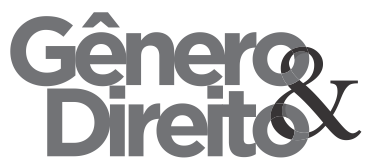

Durante muitos anos a violência

sofrida pelas mulheres não foi reconhecida como um problema social, pelo fato de ocorrer no espaço doméstico em meio às relações familiares, sendo considerada como uma questão de ordem privada. As relações patriarcais legitimavam a dominação masculina, tornando "o lar um lócus privilegiado para a violência contra mulher, tida como necessária para a manutenção da família e o bom funcionamento da sociedade (LAGE e NADER, 2012, p: 287)”.

A legislação do período colonial permitia que o marido assassinasse a esposa adúltera. $\mathrm{O}$ comportamento fora do padrão estabelecido justificava a violência como forma de disciplina, culpando a mulher pelas agressões sofridas (LAGE e NADER, 2012). Somente em 2005 o adultério deixou de ser crime no Brasil, ou seja, a ideologia patriarcal norteou a legislação justificando as diversas formas de violência contra mulheres, produzindo uma sociedade tolerante frente a violência de gênero. Confinadas em casa, as mulheres se tornam invisíveis, mantendo assim o silêncio e a ordem das coisas, perpetuando todas as formas de violência (LAGE e NADER, 2012).
Cenco do Núcleo de Estudos e Pesquisas sobre Gênero e Direito Centro de Ciências Jurídicas - Universidade Federal da Paraíba V. 6 - $\mathrm{N}^{\circ} 02$ - Ano 2017

Em decorrência das lutas feministas, muito se avançou nas políticas e legislações, como a criação do Conselho Nacional dos Direitos da Mulher em 1985; a Convenção Interamericana para Prevenir, Punir e Erradicar a Violência contra a Mulher em 1995; criação da Central de Atendimento à Mulher em Ligue 180, em 2003; e a criação da Lei 11.340, Lei Maria da Penha, em 2006.

Embora todos estes dispositivos tenham sidos criados, estudo realizado pelo sociólogo Julio Jacobo Waiselfisz, com o apoio da Faculdade LatinoAmericana de Ciências Sociais (FLACSO) e do Centro Brasileiro de Estudos LatinoAmericanos (CEBELA), aponta que, de 2001 a 2011, o índice de homicídios de mulheres aumentou $17,2 \%$, com a morte de mais de 48 mil brasileiras nesse período. Só em 2011 mais de 4,5 mil mulheres foram assassinadas no país (Mapa da Violência 2013).

As autoras Strey e Pulcherio (2010, p: 24), alertam sobre os dados da violência de gênero:

Apesar de ser um problema cada vez mais evidente, tanto nas sociedades desenvolvidas quanto nas não desenvolvidas ou em vias de desenvolvimento, é ainda difícil confiar nas estatísticas oficiais e não oficiais, devido às suas 
ISSN | 2179-7137 | http://periodicos.ufpb.br/ojs2/index.php/ged/index

características de provável invisibilidade. É de se esperar que essa violência não venha à luz em muitos dos casos por medo, vergonha, submissão. E, quando vem, também muito provavelmente será após muito tempo de esporádico ou permanente sofrimento.

Normalidade, acomodação, submissão e medo foram apontados pelas(os) pesquisadas(os) como os principais fatores que mantém as mulheres em situação de violência. Ou seja, apesar das várias políticas públicas voltadas para o enfrentamento à violência de gênero, a reprodução da violência, ainda se dá pela invisibilidade.

"Voltar para o casulo". Violência de gênero: a dinâmica que não se entende "A gente sente uma necessidade muito grande de tentar ajudar né, de tentar achar uma saída, aí a frustração vem por muitas vezes tu não achar essa saída e muitas vezes tu vê que ela veio e descarregou tudo em cima de ti, tu tentou de todas as formas achar uma luz e viu que ela vai voltar pro casulo e vai continuar da mesma forma sabe, tipo assim, ela não vai ter coragem pra fazer isso ou aquilo que tu falou pra ela (Técnica de Enfermagem ,participante da pesquisa, Agosto de 2014)”.

A incapacidade de as mulheres superarem o desafio e romperem com o ciclo de violência é, na maioria das vezes, o questionamento mais frequente da população. Esta questão, também abordada pelos pesquisados/as, independentes de suas formações ou atribuições na ESF, denota a incapacidade de compreensão da dinâmica da violência contra as mulheres.

"Isso ai, eu também me sinto frustrada às vezes, elas se queixam, e tu te dedica, e daqui a pouco, elas estão fazendo daquela pessoa que elas se queixaram, um Deus, $e$ ai tu fica perguntando, será que eles são tão felizes assim, que é o mundinho deles e eles são felizes assim e eu to querendo interferir, ou se realmente é uma situação, porque a violência existe, mas parece que estão acostumadas ali e ao mesmo tempo parece que eles estão bem, estão lá, em família, não estão sozinhos, estão bem, se ela for se separar, vai ficar sozinha, tem toda uma luta pela frente, e a gente fica também meio assim, sem saber muito o que fazer, quando a pessoa fica nesse vai e vem né. (Médica, participante da pesquisa, agosto de 2014)".

Narvaz e Koller (2006) discutem sobre a complexidade das questões envolvidas na dinâmica da violência 
contra as mulheres, destacando as relações de poder, gênero, classe social, alcoolismo e transmissão de padrões abusivos de relações através de gerações, para compreensão deste complexo fenômeno. "Diferentes posições, ora de submissão, ora de resistência, têm sido encontradas na pesquisa e na literatura científica no que concerne à questão das mulheres que são agredidas por seus parceiros (p.9)".

Tal dinâmica, incompreensível para a população pesquisada, sinaliza que o olhar sobre a saúde das mulheres não questiona a desigualdade entre os gêneros como fator de produção da vulnerabilidade e manutenção das diversas formas de violência.

\section{SOBRE A CULPABILIZAÇÃO}

"A liberdade da mulher pode causar a violência": a velha história da culpabilização.

A liberdade das mulheres tem sido pauta constante nas lutas feministas. Muito se tem conquistado, desde políticas públicas, melhores condições no mundo do trabalho e lei de proteção em situações de violência. A independência financeira, embora a desigualdade salarial ainda persista, tem aumentado gradativamente, com o acesso à escolarização e ao trabalho remunerado. Embora todos esses avanços sejam reconhecidos pelas mulheres, uma questão bastante pertinente tem nos saltado aos olhos. O essencial para as mulheres é a conquista pela liberdade, porém subjetivamente as mulheres ainda não reconhecem esse espaço "de liberdade" no sentido mais amplo. Pesquisa realizada em 2012, onde a temática sobre a liberdade foi discutida com mulheres do movimento social MMC - Movimento de Mulheres Camponesas, apontou que a participação no movimento se constitui como um espaço de aprendizado que lhes possibilita a conquista desta liberdade, porém elas sentem-se culpadas e causadoras de sofrimento para seus companheiros e sua família (CARDOSO e WERBA, 2012).

Novamente, nesta pesquisa, o exercício da liberdade é trazido a baila, e desta vez as pesquisadas apontam que esse pode ser um elemento causador de violência.

"Talvez o homem se sinta mais inseguro em relação a isso né. Que antes era ele que tava no topo da situação e agora ta se sentindo ameaçado". (Agente Comunitária de Saúde, 
participante da pesquisa, agosto de 2014)”.

"E quando por essa evolução da mulher, é por isso que os homens abafam as mulheres, pra não deixar ela criar asinhas e querer o mundo, é o medo que eles tem, então ela vai ficar aqui oh, cuidando da casa pra mim e se eu der asas pra ela, ela vai voar.Isso é uma grande agressão. Deixar a pessoa proibir a pessoa de viver, porque tem medo de ela ir embora. (Técnica em Enfermagem, participante da pesquisa, agosto de 2014)".

É interessante percebermos que, mesmo reconhecendo que se trata de violência, as pesquisadas não se colocam de forma crítica diante desta dinâmica e afirmam, até mesmo de forma preconceituosa, que a liberdade das mulheres pode justificar atos de violência. "É que a mulher confundiu liberdade com libertinagem, que tem a liberdade feminina, que pode estudar, a profissão, independência financeira, só que daí muitas mulheres confundiram isso com libertinagem mesmo, pode ter um homem hoje outro amanhã, pode transar com um homem hoje, isso ai é muito preconceituoso (Agente Comunitária de Saúde, participante da pesquisa, agosto de 2014)".
Para Touraine (2007) a conduta

feminina difundida pela mídia vai de um polo a outro, da criação de si à busca utilitária do prazer, como oferta máxima de libertação. E neste sentido o autor aponta que:

O desejo da criação de si não funciona sem uma liberdade de corpo e da sexualidade e, ao mesmo tempo, sem a concretização de projetos profissionais novos e uma concepção diferente das relações com os outros. No nível da vida privada, esta combinação do enfraquecimento das barreiras antigas, da realização dos desejos pessoais e da influência da mídia determina em seu mais alto nível o que se deve denominar de costumes. O fato mais visível a este respeito é que o enfraquecimento dos papéis sociais das mulheres as levam a cultivar simultaneamente a vontade de criação de si, o sucesso social e o prazer. Mas esta pluralidade de orientações supõe uma autonomia, uma liberdade maior em matéria de sexualidade, e ninguém duvida que esta tenha aumentado num passado recente, mesmo se o começo do século XXI ainda esteja marcado pelo selo da restrição em todas as ordens de liberdade, em particular a sexual (p: 170).

Este tem sido um paradoxo vivenciado pelas mulheres pesquisadas, apontando que os preconceitos sustentam as relações assimétricas entre os gêneros e justificam as relações de dominação. Tal fato nos leva a questionarmos o movimento de mulheres, afinal, de onde viemos e para onde vamos? Por que não 


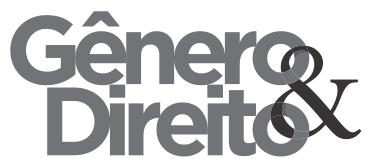

legitimamos todas as conquistas? O que todas nós mulheres reconhecemos como conquistas de fato? Conquistamos a tão desejada liberdade?

\section{CONSIDERAÇÕES FINAIS}

Mesmo com o avanço das políticas públicas para o enfrentamento da violência de gênero, o setor de saúde ainda não reconhece esta problemática como de sua competência. Esta afirmativa se faz mesmo diante de quadros epidemiológicos que apontam a violência como um fenômeno cada vez mais presente na vida das brasileiras. Diante desta realidade também abordada por outras pesquisas, optamos por utilizar as teorias das Representações Sociais e Gênero a fim de que possamos melhor compreender esse fenômeno explicado, mas não compreendido. Sabendo de antemão que: o modelo biomédico, a falta de capacitação dos profissionais, a pouca estrutura do sistema de saúde, a desresponsabilização dos serviços, a rede de apoio falha e a impotência vivenciada pelos profissionais diante das situações de violência, são fatores apontados como entraves no atendimento à mulheres em situação de
Cen do Núcleo de Estudos e Pesquisas sobre Gênero e Direito Centro de Ciências Jurídicas - Universidade Federal da Paraíba V. 6 - $\mathrm{N}^{\circ} 02$ - Ano 2017

191

violência, poderíamos pensar que as respostas já estariam dadas. Para além destas pesquisas e respostas já obtidas, a nossa tarefa foi explorar o saber construído sobre a violência contra mulher no âmbito da Atenção Básica. Para Jovchelovitch (2011, p: 259) “todo saber é expressivo, pois procura representar mundos subjetivos, intersubjetivos e objetivos". Reconhecendo que toda representação consiste numa construção ativa de atores sociais, e que esta dinâmica se dá do individual ao social e do social ao individual, entendemos que compreender o fenômeno da violência contra mulher através desta ótica, propiciará o desenvolvimento da capacidade crítica e autocrítica, estabelecendo assim novos elementos para o desenvolvimento de todos os saberes e do potencial emancipatório.

Durante a elaboração da pesquisa, três categorias foram pinçadas para análise: Invisibilidade, Culpabilização e Intervenções.

Para as/os pesquisadas/os a violência contra mulher se dá pelas relações patriarcais instituídas, onde o espaço doméstico é o lócus de ordem privada e a submissão aparece como 
resposta a esta ordem. O medo foi outro fator apontado como causador da invisibilidade, mantendo as mulheres em situação de acomodação e não enfrentamento desta situação.

A culpabilização foi alvo de discussão acirrada entre as/os participantes da pesquisa, para eles e elas os transtornos afetivos e de personalidade poderiam ser considerados como causadores de situações de violência, suscitando o modelo biomédico de entendimento e funcionamento da saúde da mulher.

O ponto considerado por nós como o mais intrigante vem da categoria culpabilização. Para as/os pesquisadas/os a liberdade da mulher é apontada como causa principal da violência praticada contra mulheres. Um paradoxo provocativo, já que a liberdade associada à emancipação financeira, ao direito de expressão e à proteção contra a violência dada pela Lei Maria da Penha, para muitas mulheres não se legitimam como conquistas em prol da igualdade entre mulheres e homens.

$\mathrm{Na}$ busca pelo entendimento desse fenômeno retomamos a história do movimento feminista brasileiro, Soibet (2014) em seu artigo sobre esta história, afirma que o movimento liderado por Bertha Luz sofreu limitações importantes no que se refere ao principal objetivo: a libertação feminina. Para a autora escaparam aos ideais do movimento vários dos fatores que impediram, plenamente, tal libertação. A conquista de participação política não implicava uma reformulação no âmbito das obrigações familiares distintas para mulheres e homens, as responsabilidades domésticas ainda eram de competência das mulheres. Por isso, ao se dedicarem ao trabalho e participação política se sentiam divididas e culpadas. Esta análise deu origem ao slogan "O pessoal é político", indicando a importância da transformação das relações cotidianas entre homens e mulheres para além do mundo doméstico.

Reconhecendo que muito foi conquistado pelo movimento feminista, esta pesquisa nos propiciou uma reflexão apontando a necessidade de uma reavaliação do principal objetivo feminista “a libertação feminina”, para assim pensarmos em estratégias efetivas de combate a violência de gênero na área da saúde. 


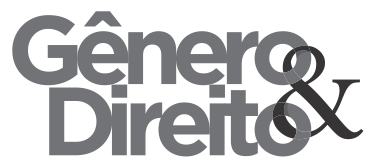

REFERÊNCIAS BIBLIOGRÁFICAS

BARDIN, L.(2007). Análise de Conteúdo.

Rio de Janeiro: Edições 70.

BRASIL. Ministério da Saúde. Portaria 648, 2006. Consultado em 22.09.2014

Disponível

em:

http://dtr2001.saude.gov.br/sas/PORTARI AS/Port2006/GM/GM-648.htm

BRASIL. Ministério da Saúde. Secretaria de Atenção à Saúde. Departamento de Atenção Básica 2012.

CARDOSO, Dione Matos de Souza; WERBA, Graziela Chucchiarelli.(2013). "Ser Mulher e Militante: a Vontade de Articular Mundos”. Revista Diálogo, n 24, p. 21 - 34. Disponível em: http://www.revistas.unilasalle.edu.br/inde x.php/Dialogo. Consultado em: 22. 09. 2014.

COSTA, Ana Maria; SILVESTRE, Rosa Maria.(2009). "Uma Reflexão Sobre Poder, Mulher e Saúde”. In: VENTURI, Gustavo; RECAMÁN, Marisol; OLIVEIRA, Suely (Orgs.). A Mulher Brasileira nos Espaços Público e Privado.
DIREITOS HUMANOS. Gabinete de documentação e direito comparado Declaração Sobre A Eliminação Da Violência Contra As Mulheres. Disponível em:

http://direitoshumanos.gddc.pt/3_4/IIIPA G3 4 _ 7.htm. Consultado em: 22. 09. 2014.

GUEDES, Rebeca Nunes; FONSECA, Rosa Maria Godoy Serpa; EGRY, Emiko Yoshikawa.(2013). "Limites e Possibilidades Avaliativas da Estratégia Saúde da Família para a Violência de Gênero". Revista Enfermagem -USP. Disponível em www.ee.usp.br/reeusp/. Consultado em: 24. 09. 2014.

JODELET, D.: Représentationssociales: Undomaine en Expansion. In D. Jodelet (Ed.) Les Représentationssociales. Paris: PUF, 1989, pp. 31-61. Tradução: Tarso Bonilha Mazzotti. Revisão Técnica: Alda Judith Alves-Mazzotti. UFRJ- Faculdade de Educação, dez. 1993.

JOVCHELOVITCH, Sandra.(2011). Os contextos do Saber - Representações, 


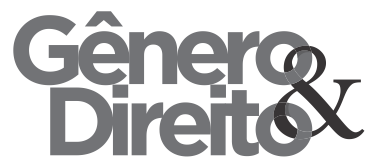

Comunidade e Cultura. Tradução

Pedrinho Guareschi. Petrópolis. Vozes.

LAGE, Lana; NADER, Maria

Beatriz.(2012). " “Da legitimação à

Condenação Social”. In. PINSKY, Carla

Bassanezi; PEDRO, Joana Maria. Nova

História das Mulheres. São Paulo:

Contexto.

NARVAZ, Martha Giudice; KOLLER, Silvia Helena (2006). "Mulheres vítimas de violência doméstica. Compreendendo subjetividades assujeitadas". PSICO, Porto Alegre, PUCRS, v. 37, n. 1, pp. 7-13, jan./abr.

PRIORE, Mary Del (Org).(2007). A História das Mulheres do Brasil. São Paulo. Contexto.

(2009). Ao

Sul do Corpo - Condição Feminina, Maternidades e Mentalidades no Brasil Colônia. São Paulo: Editora UNESP.

STREY, Marlene Neves.(2000). JACQUES, M. G et al. Psicologia Social Contemporânea.Petrópolis: Vozes.
Cenco do Núcleo de Estudos e Pesquisas sobre Gênero e Direito Centro de Ciências Jurídicas - Universidade Federal da Paraíba V. 6 - $\mathrm{N}^{\circ} 02$ - Ano 2017

STREY, Marlene Neves; PULCHERIO, Gilda.(2010). "As tramas de Gênero na Saúde”. In. STREY, Marlene Neves; NOGUEIRA, Conceição; AZAMBUJA, Mariana Ruwer (Org). Gênero e Saúde: Diálogos Ibero-Brasileiros. Porto Alegre: EDIPUCRS.

TOURAINE, Alain.(2007). O mundo das mulheres; Tradução de Francisco Morás. Petrópolis: Vozes.

WAISELFISZ, Julio Jacobo.(2012) Mapa da violência . Atualização: homicídio de mulheres no Brasil. CEBELA - Centro Brasileiro de Estudos Latino-Americanos. Consultado em: 24. 09. 2014.

WERBA, Graziela C. (1999). "Parteiras, Bruxas, Mulheres... Articulações entre a saúde, o Poder e o Feminino na História”. In: STREY, Marlene N. (org). Gênero por Escrito. Saúde, Identidade e Trabalho. Porto Alegre: Edipuc. 